\title{
Malignant melanoma of the choroid in a naevus of Ota
}

\author{
MOHINDER SINGH,' BALJIT KAUR,' AND NORIZAN MOHD ANNUAR \\ From the Departments of 'Ophthalmology and ${ }^{2}$ Pathology, National University of Malaysia, \\ Kuala Lumpur, Malaysia
}

SUMMARY A rare case of choroidal malignant melanoma in a naevus of Ota is described. This is the first reported case from Asia outside the Japanese population. This case illustrates the need for close observation of all pigmented lesions of the eye.

Naevus of Ota or 'Oculodermal melanocytosis' is a congenital hyperpigmentation of the facial skin in the distribution of the first and second divisions of the trigeminal nerve which is often associated with increased pigmentation of the various ocular structures. ' Malignant change in the naevus of Ota is rare, and when involving the choroid it has been reported mostly in Caucasians. ${ }^{2}$ Only four such cases have been seen in the Oriental population. ${ }^{3}$

We describe a case of choroidal malignant melanoma in the naevus of Ota in a Malay woman.

\section{Case report}

A 72-year-old Malay woman was admitted to the medical ward of the General Hospital, Kuala Lumpur, on 19 December 1984 with a one-week history of loss of weight and appetite, abdominal distension, and passing dark coloured urine. She also complained of slight watery discharge of her right eye on and off. She had been blind in the right eye for four years and had frequent episodes of ocular pain. Her right eyeball as well as right periocular skin had been pigmented since childhood.

On examination she looked emaciated, severely jaundiced, and had moderate ankle oedema. The abdomen was distended. Ascites was present along with a markedly enlarged liver, which was firm, nodular, and not tender. The spleen was palpable.

\section{INVESTIGATIONS}

Liver function tests confirmed severe hepatic damage. Tests for $\alpha$-fetoprotein and hepatitis B surface antigen were negative. While she was being investigated for the cause of liver failure she was Correspondence to Mohinder Singh, FRCS, 37 Norman Road, Ilford, Essex IG1 2NH, England. referred to the eye clinic because of her discharging right eye.

Ophthalmological findings. Light perception was absent in the right eye and she could only count fingers at $1 \mathrm{~m}$ with her left eye. Several irregular patches of bluish scleral pigmentation were visible in all quadrants. The right eyeball was slightly congested, and dilated episcleral vessels were prominent. Black episcleral nodules were also noted at the upper limbus as well as near the superior fornix. The lower two-thirds of the cornea was densely opaque. There was no outline of the pupil (Fig. 1). A fundus

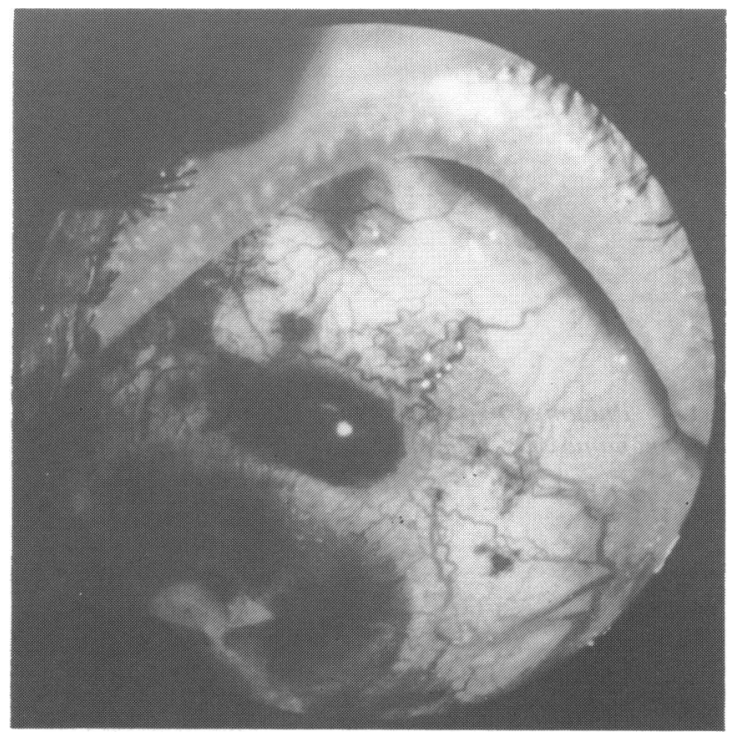

Fig. 1 Photograph showing episcleral pigmentation and black nodule. Dilated subconjunctival vessels are also visible. 


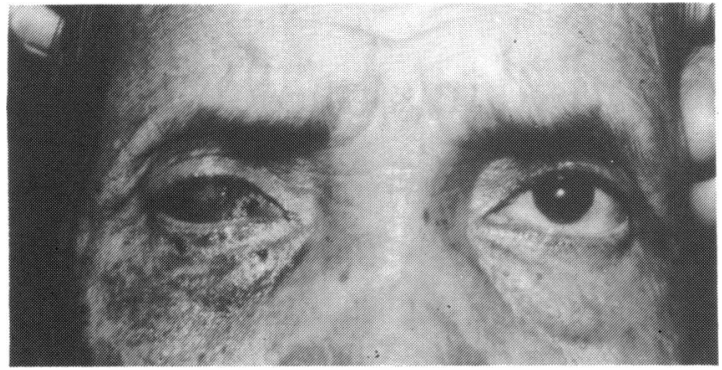

Fig. 2 Photograph showing pigmentation of the right periocularskin.

view was not possible and the eye felt hard to palpation. The left eye showed yellow discolouration of the sclera and the left lens was cataractous. No other abnormality was detected in the left eye.

Dermatological findings. Dark blue pigmentation of the skin involving the right upper and lower lids as well as part of the right cheek and right temple was present (Fig. 2).

A clinical diagnosis of malignant melanoma in a naevus of Ota with metastasis in the liver was made. On further questioning the patient stated that she had attended the eye clinic four years previously for severe right visual loss. She was advised to have her right eye removed but had refused, and she defaulted from further follow-up. The presence of a raised, solid, pigmented lesion involving the right macular area and reaching the temporal edge of the right optic disc was recorded in her old case notes in the eye clinic.

The right eye was enucleated on 20 December 1984

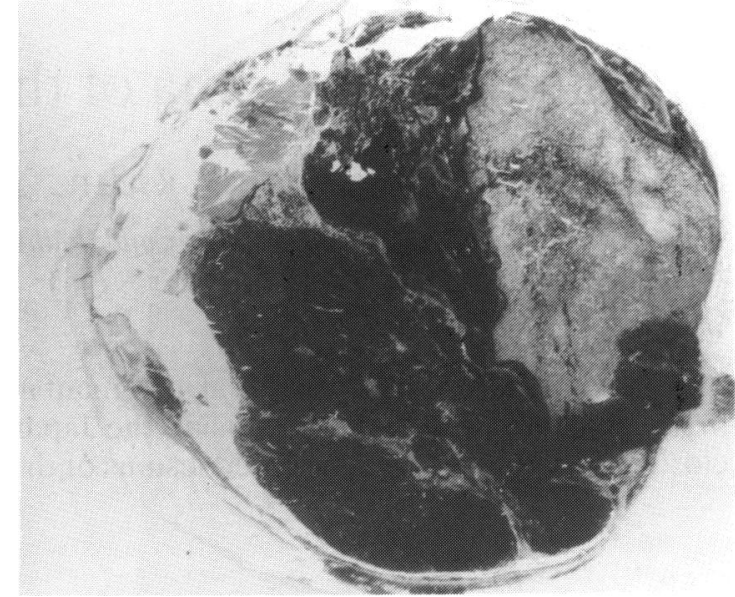

Fig. 3 Photograph of the sectioned eyeball showing the tumour mass filling the vitreous cavity and invasion of the optic nerve.

and the patient died four days later. A post-mortem specimen of liver was taken.

PATHOLOGICAL FINDINGS

The enucleated eyeball measured $25 \times 25 \times 25 \mathrm{~mm}$; the attached optic nerve was $7 \mathrm{~mm}$ in length and $5 \mathrm{~mm}$ in diameter. The lower part of the cornea was opaque. Multiple darkish nodules, the largest measuring $6 \times 3 \times 1 \mathrm{~mm}$, were seen over the sclera. The eyeball was sectioned through the meridional plane. It was completely filled with a dark solid mass. There was infiltration of the optic nerve and sclera.
Fig. 4 Photomicrographshowing the melanoma cells. $H$ and $E$.

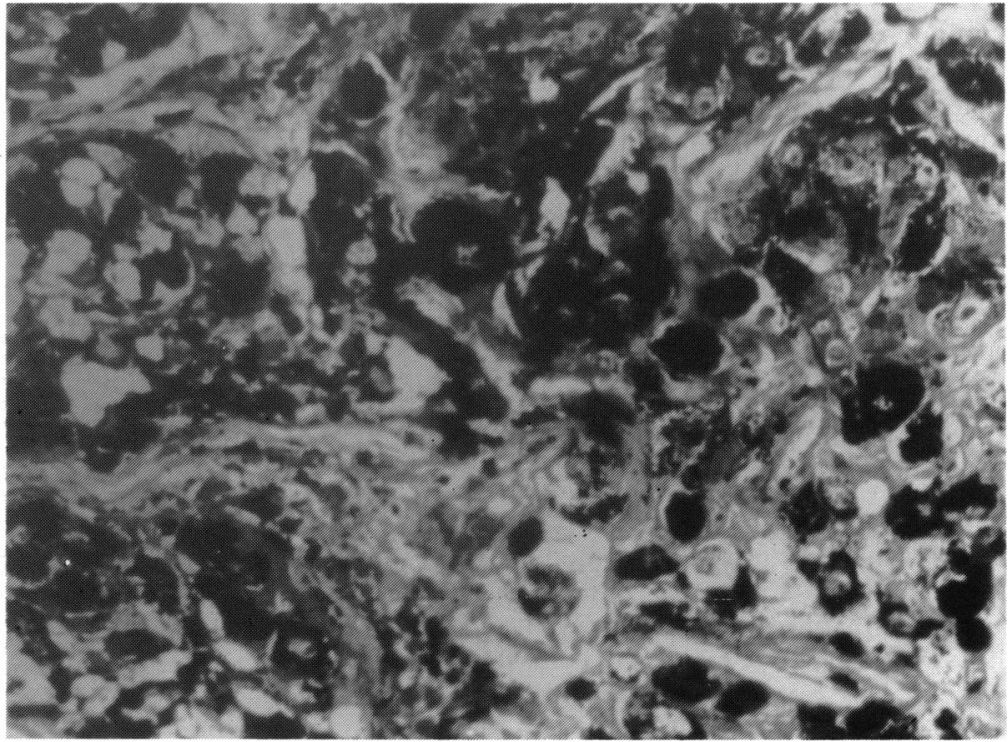


The lens was displaced and fragmented at its periphery by infiltration of the dark mass. The anterior chamber was filled with tumour tissue (Fig. 3).

Microscopically pigmented dendritic melanocytes were found within the superficial sclera. The mass was composed mainly of polygonal malignant cells containing heavily pigmented cytoplasm and round nuclei with prominent nucleoli. Mitotic figures were frequently present. Large areas of necrosis were seen within the mass. There was infiltration of the sclera, angle structures, and the entire optic nerve by malignant cells (Fig. 4).

The histopathological diagnosis was malignant melanoma of epithelioid type. Histopathology of the liver material also showed melanoma cells.

\section{Discussion}

Malignant melanoma of the eye is rare in Orientals, though relatively common in Caucasians. All pigmented lesions of the eye in a white person are therefore closely watched for fear that they might become malignant at any time during the life of that individual. One such pigmented lesion of the eye is the naevus of Ota. Clinically and histologically the episclera and the choroid have been observed to be involved by the melanocytic process in almost all cases of oculodermal melanocytosis. ${ }^{2}$ Malignant change in the naevus of Ota has been reported involving the skin, ${ }^{4}$ choroid, ${ }^{3 .-x}$ iris, ${ }^{9}$ orbit, ${ }^{1111}$ and brain. ${ }^{12}$

Naevus of Ota is common in the Oriental population but malignant change in these cases is regarded as extremely rare. On the other hand naevus of Ota is considered to have a high potential for malignancy when it does occur on rare occasions in the white races. ${ }^{21314}$ It is generally recommended that a naevus of Ota in a white person should be kept under close observation. On the basis of the present report we suggest that, since malignant change is possible in naevus of Ota in an Oriental, all such cases should also be kept under observation.

Primary ocular malignancy as the cause of terminal illness in our patient was not recognised by the medical staff until she was seen by us. We feel that it is often not well appreciated in the Oriental popula- tion that widespread metastatic disease can result from primary neoplasm in the eye, and the result may be that the patient undergoes unnecessary invasive investigations. Lack of understanding of the nature of the disease in our patient prevented her from consenting to enucleation when malignancy was detected in her eye four years previously. We believe there is a great need to educate the public about diseases like treatable cancer.

We thank Encik Alias Manap for the photographic work and Puan Nurul Amani Mohd Danin for her secretarial help.

\section{References}

1 Fitzpatrick TB, Zeller R, Kukita A, Kitamura H. Ocular and dermal melanocytosis. Arch Ophthalmol 1956; 56: 830-2.

2 Gonder JR, Shields JA, Albert DM, Augsburger JJ, Lavin PT. Uveal malignant melanoma associated with ocular and oculodermal melanocytosis. Ophthalmology 1982; 89: 953-60.

3 Lo C, Kiribuchi T, Maruo T. Malignant melanoma of the choroid associated with the nevus of Ota. In: Shimuzu K, Oosterhuis JA, eds. Ophthalmology. International Congress Series 450. Amsterdam: Excerpta Medica, 1979; 2: 1959-62.

4 Dorrey CS, Montgomery $\mathrm{H}$. Blue nevus and its distinction from Mongolian spot and the nevus of Ota. J Invest Dermatol 1954; 22: 225-36.

5 Hulke JW. A series of cases of carcinoma of the cyeball. $R$ Lond Ophthalmic Hosp Rep 1961; 3: 279-86.

6 Albert DM, Scheic HG. Nevus of Ota with malignant melanoma of the choroid: report of a case. Arch Ophthalmol 1963; 69: $774-7$.

7 Yamamoto T. Malignant melanoma of the choroid in the nevus of Ota. Ophthalmologica 1969; 159: 1-10.

8 Gondel JR, Shields JA, Albert DM. Malignant melanoma of the choroid associated with oculodermal melanocytosis. Ophthalmology 1981; 88: 322-76.

9 Font RL, Reynolds AM Jr, Zimmerman LE. Diffuse malignant melanoma of the iris in the nevus of Ota. Arch Ophthalmol 1967; 77: 513-8.

10 Jay B. Malignant melanoma of the orbit in a case of oculodermal melanosis (naevus of Ota). Br J Ophthalmol 1965; 49: 359-63.

11 Hagler WS, Brown CC. Malignant melanoma of the orbit arising in a nevus of Ota. Ophthalmology 1966; 70: 817-22.

12 Sang DN, Albert DM, Sober AJ, McMeekin TO. Nevus of Ota with contralateral cerebral melanoma. Arch Ophthalmol 1977; 95: $1820-4$

13 Reese AB. Melanosis oculi: a case with microscopic findings. Am J Ophthalmol 1925; 8: 865-70.

14 Yanoff M, Zimmerman LE. Histogenesis of malignant melanoma of the uvea III. The relationship of congenital ocular melanocytosis and neurofibromatosis to uveal melanomas. Arch Ophthalmol 1967; 77: 331-6.

Accepted for publication 15 December 1986. 